\title{
Experimental alveolitis in rats: microbiological, acute phase response and histometric characterization of delayed alveolar healing
}

\author{
Moacyr Tadeu Vicente RODRIGUES ${ }^{1}$, Camila Lopes CARDOSO², Paulo Sérgio Perri de CARVALHO ${ }^{3}$, Tânia Mary \\ CESTARI $^{4}$, Magda FERES ${ }^{5}$, Gustavo Pompermaier GARLET ${ }^{6}$, Osny FERREIRA JÚNIOR
}

\author{
1- DDS, MSc, Assistant Professor of Surgery, São Lucas School, Porto Velho, RO, Brazil. \\ 2- DDS, MSc, PhD student, Department of Stomatology, Bauru School of Dentistry, University of São Paulo, Bauru, SP, Brazil. \\ 3- DDS, MSc, PhD, Professor, Department of Stomatology, Bauru School of Dentistry, University of São Paulo, Bauru, SP, Brazil. \\ 4- DDS, MSc, PhD, Department of Biological Sciences, Bauru School of Dentistry, University of São Paulo, Bauru, SP, Brazil. \\ 5- DDS, MSc, PhD, Dental Research Division, Guarulhos University, Guarulhos, SP, Brazil. \\ 6- DDS, MSc, PhD, Associate Professor, Department of Biological Sciences, Bauru School of Dentistry, University of São Paulo, Bauru, SP, Brazil. \\ 7- DDS, MSc, PhD, Associate Professor, Department of Stomatology, Bauru School of Dentistry, University of São Paulo, Bauru, SP, Brazil.
}

Corresponding address: Camila Lopes Cardoso - Faculdade de Odontologia de Bauru - FOB - USP - Departamento de Estomatologia - Alameda Octávio Pinheiro Brizola, 9-75 - 17012-901 - Bauru, São Paulo - Brasil - Phone +55-14-3235-8248 - Fax +55-14-3235-8251 - e-mail: cardoso_lopes@yahoo.com.br

Received: June 5, 2009 - Modification: February 16, 2010 - Accepted: March 26, 2010

\section{ABSTRACT}

\begin{abstract}
The pathogenesis of alveolitis is not well known and therefore experimental situations that mimic some features of this disease should be developed. Objective: In this study, the evolution of the experimentally induced infection in rat sockets is characterized, which leads to clinical signs of suppurative alveolitis with remarkable wound healing disturbs. Material and methods: Non-infected (Group I) and experimentally infected sockets in Rattus novergicus (Group II) were histometrically evaluated regarding the kinetics of alveolar healing. In addition, the characterization of the present bacteria in inoculation material and the serum levels of C-reactive protein (CRP) were performed. The detected species were Capnocytophaga ochracea, Fusobacterium nucleatum ss nucleatum, Prevotella melaninogenica, Streptococcus anginosus, Treponema socranskii and Streptococcus sanguis. Results: All experimentally infected rats developed suppurative alveolitis, showing higher levels of CRP in comparison to those non-infected ones. Furthermore, infected rats presented a significant delayed wound healing as measured by the histometric analysis (higher persistent polymorphonuclear infiltrate and lower density of newly formed bone). Conclusion: These findings indicate that rat sockets with experimentally induced infection produced higher levels of serum CRP, showing the potential of disseminated infection and a disturb in the alveolar repair process in an interesting experimental model for alveolitis studies.
\end{abstract}

Key words: Dry socket. Tooth extraction. C-reactive protein. Alveolitis.

\section{INTRODUCTION}

Alveolitis is one of the most common postoperative complications following the extraction of permanent teeth. It is a complication characterized by severe pain starting between the first and third day after extraction, associated with an empty socket completely or partially filled of a normal blood clot with or without halitosis ${ }^{5}$ In addition to the local symptoms, acutely infected sockets can be associated with signs of systemic infection, such as fever $^{8}$. The incidence of alveolitis has been reported to range from 3 to $4 \%$ following routine dental extractions, and from 1 to $45 \%$ after removal of mandibular third molars ${ }^{5,29}$. The most widely accepted hypothesis points to increased fibrinolytic disintegration of the blood clot triggered by infection and/or surgical trauma as the etiologic factor of alveolitis ${ }^{4,5}$. Nitzan, et al. ${ }^{19}$ (1978) showed a possible role of anaerobic microorganisms, which are also the 
predominant microorganisms in pericoronitis related to the etiology of alveolitis. Moreover, other factors are considered as contributors to the occurrence of alveolitis, including female gender, tobacco use, oral contraceptives, low operator experience, mandibular teeth, and overzealous irrigation or curettage of the socket after extraction $2,5,9,14,15,17,18,25-27$. The extreme distress and pain suffered by patients with alveolitis, as well as the loss of work days and the need of numerous treatment sessions, make this complication equally costly for patients and dentists. At least $45 \%$ of patients will need four or more appointments in order to achieve a complete solution of symptoms ${ }^{12,13}$.

The term "treatment" can be quite misleading when used in the context of alveolitis as this condition cannot be correctly treated in the absence of a firmly established underlying etiology. Clinical management is directed towards reassurance and prompt pain relief until normal healing process starts. In an attempt to reduce the incidence of alveolitis, different local and systemic approaches have been adopted; namely, the use of antibiotics, antiseptic agents with lavage, antifibrinolytic agents, obtundent dressings, antiinflammatory drugs, and clot-supporting agents ${ }^{5,6,14,18,25,28}$.

Considering that healing may be disturbed even in normal healthy patients ${ }^{1}$, the assessment of healing in extraction sockets, especially under disturbed healing, is considerably important, also considering further rehabilitation with dental implants or other procedures. Comparison of different socket medicaments and their effects on alveolar wound healing and infection resolution is a goal that can be achieved through the assessment of socket healing. In addition, factors responsible for promoting or delaying healing can also be ascertained through the same approach. However, several variables thought to be involved in disease pathogenesis affecting the interpretation of human studies, and the exact mechanisms involved in alveolitis onset are not completely known, therefore, making it difficult to prevent and impairing the development of most effective therapeutic strategies. Consequently, experimental rat models may be extremely useful to alveolitis studies, since they present several advantages including easy handling, availability of experimental reagents and susceptibility of suppurative alveolitis induction.

The aim of this study was to characterize a rat model of experimentally induced alveolitis by investigating the levels of C-reactive protein (CRP) and determining the bacterial species present in inoculation material used for disease induction related to the histometrical features of the delayed wound healing.

\section{MATERIAL AND METHODS}

\section{Experimental alveolitis}

Thirty 10 week-old male Wistar rats (Rattus novergicus albinus) weighing about $250 \mathrm{~g}$ were used in this study. The animals were submitted to coproparasitological test in which pathogenic parasites were not found. The animals were kept in individual cages previously disinfected and covered by sterile sawdust. Before and during the experimental phase, the animals were fed with solid chow (Anderson \& Clayton S.A., São Paulo, SP, Brazil), except for the first 24 postoperative hours, when ground chow was offered. The rats received sterile water ad libitum throughout the study. The experimental protocol was approved by the local Institutional Committee for Animal Care and Use.

For surgical interventions (Figure 1), the animals received a preanesthetic medication consisting of an intramuscular injection of xylazine hydrochloride (15 mg/kg body weight) in the back of the thigh. Further anesthesia followed by a combination of ketamine hydrochloride (25 mg/kg body weight) and xylazine hydrochloride (10 $\mathrm{mg} / \mathrm{kg}$ body weight) via intramuscular injection in the same region. Asepsis of the anterior portion of the maxilla was carried out with $2 \%$ chlorhexidine solution and the maxillary right central incisor was extracted ${ }^{21}$. The animals were randomly assigned to 2 groups: Group I, in which the sockets were filled with blood clot (to allow the normal repair), and Group II, which received an intra-alveolar application of epinephrine solution 1:1,000 (Ariston Ind. Farm. Ltda, São Paulo, SP, Brazil) with an absorbent paper point (Sybon Kerr, Orange, CA, USA) during 1 min followed by application of suppurative secretion obtained from donor rats using an absorbent paper point during $1 \mathrm{~min}$.

The suppurative secretion was obtained from rats that received the application of absorbent paper points containing $1: 1,000$ epinephrine solution in socket immediately after the extraction of right maxillary incisor 1 min followed by application of reduction medium (MRT) using sterile paper points. This procedure resulted in suppurative alveolitis clinically detectable 3 days after extraction. However, due to a high variability in the onset of experimental alveolitis, these animals were used as previously standardized suppurative secretion donors. The collected alveolar secretion was cultured in thioglycollate medium, stored at $-196^{\circ} \mathrm{C}$, and then used as aforementioned, resulting in a $100 \%$ efficacy of experimental alveolitis induction in the test group, clinically similar to the one observed in the donor rats.

At 6,15 , and 28 post-extraction days, 5 animals from each group were euthanized with a massive dose of anesthetics. 


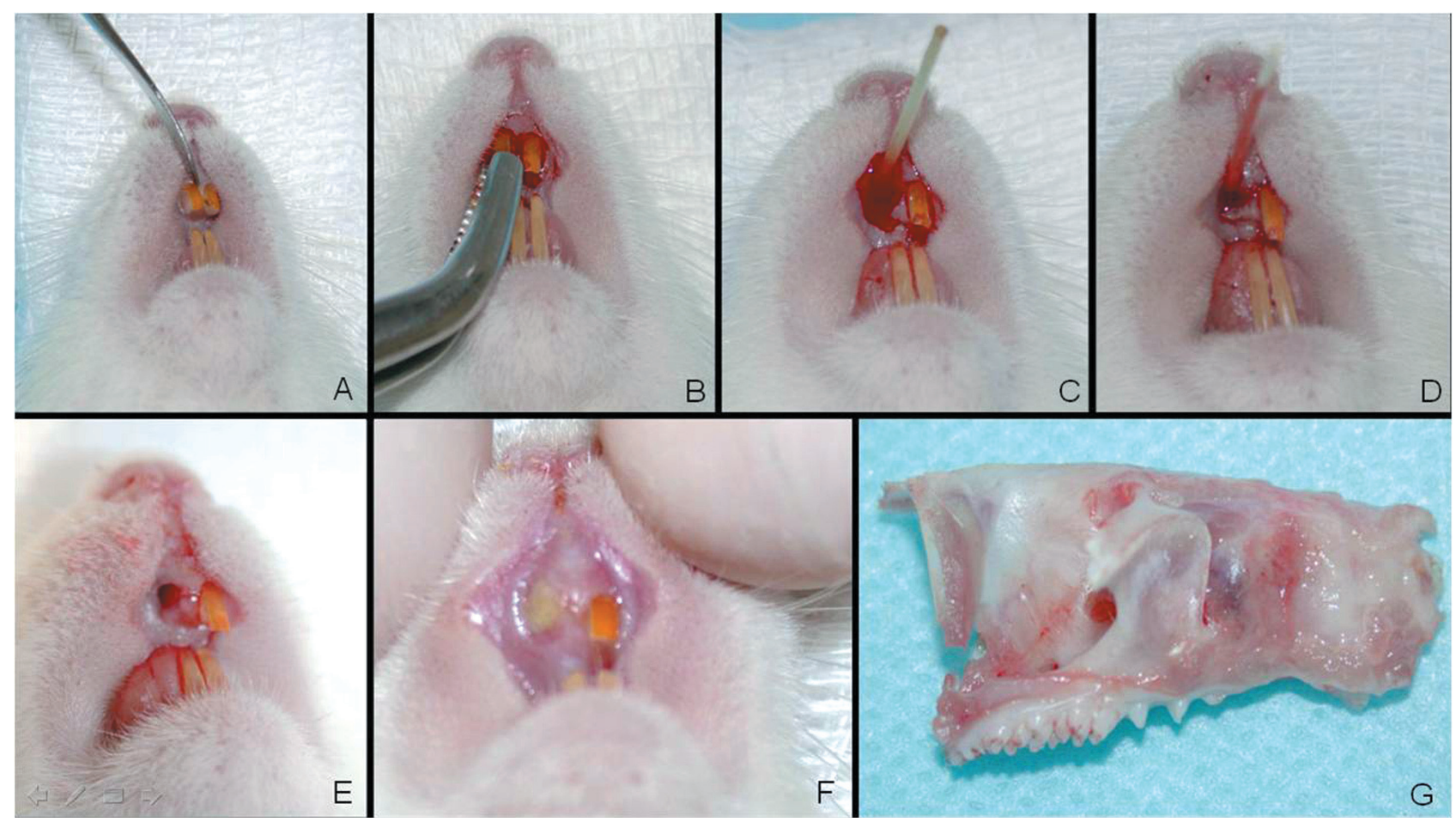

Figure 1- Experimental procedures for experimental alveolitis induction in rats. A) Luxation of right maxillary incisor; B) Extraction; C) Application of adrenaline solution 1:1,000 1 min; D) Inoculation of purulent secretion into the socket; E) Socket aspect after ischemia and contamination; F) Socket aspect after 3 days of contamination showing pus and gingival edema; G) Right maxilla specimen obtained to histological process.

\section{Checkerboard DNA-DNA hybridization}

The presence of 39 subgingival species (Table 1) was investigated in the inoculation material by checkerboard DNA-DNA hybridization ${ }^{24}$. Three samples of secretion, before inoculation, were placed in separate Eppendorf tubes containing 0.15 $\mathrm{mL}$ TE (10 mM Tris-HCl, 1 mM EDTA, pH 7.6). 0.15 $\mathrm{mL}$ of $0.5 \mathrm{M} \mathrm{NaOH}$ was added to each tube and the samples were dispersed using a vortex mixer. The samples were boiled for $10 \mathrm{~min}$ and neutralized using $0.8 \mathrm{~mL}$ of $5 \mathrm{M}$ ammonium acetate. The released DNA was then placed into the extended slots of a Minislot-30 apparatus (Immunetics, Cambridge, MA, USA), concentrated onto a $15 \times 15 \mathrm{~cm}$ positively charged nylon membrane (Boehringer-Mannheim, Indianapolis, IN, USA) and fixed to the membrane by baking at $120^{\circ} \mathrm{C}$ for $20 \mathrm{~min}$. The membrane was placed in a Miniblotter 45 (Immunetics) with the lanes of DNA at $90^{\circ}$ to the lanes of the device. Digoxigenin-labeled whole genomic DNA probes to 39 subgingival species were hybridized in individual lanes of the Miniblotter. After hybridization, the membranes were washed at high stringency and the DNA probes detected using antibody to digoxigenin conjugated with alkaline phosphatase and chemiluminescence detection ${ }^{10}$.

\section{Serum C reactive protein (CRP) measurement}

The levels of serum CRP were determined in attempt to investigate a possible systemic involvement of induced alveolar infection, as previously described ${ }^{8}$. It was used a commercially available agglutination kit (Labtest Diagnóstica, São Paulo, SP, Brazil). In brief, $50 \mu \mathrm{L}$ of serum samples from 5 animals per group at $0,3,6$, 15 and 28 days (diluted 4, 16, 64, 128 and 256 times), $50 \mu \mathrm{L}$ of $0.9 \% \mathrm{NaCl}$ and $50 \mu \mathrm{L}$ of a solution containing latex beads coated with anti-CRP antibodies were dispensed in 96-well plates. The plate was agitated with circular movements for 2 min, and the macroscopic evidence of agglutination was observed. For the semiquantification of CRP levels, the level of assay sensitivity ( $>6 \mathrm{mg} / \mathrm{L}$ ) was multiplied by the titre of CRP of each sample. The test was repeated 3 times in order to confirm the results ${ }^{11}$.

\section{Histometric Analysis}

The maxilla was separated from the mandible and the right hemimaxilla recovered. Samples were fixed in $10 \%$ buffered formalin for 7 days, decalcified in $4.7 \%$ EDTA pH 7.0 for 35 days, histologically processed, and embedded in paraffin wax. All samples were embedded to provide longitudinal cuts. Semi-serial 5- $\mu$ m-thick longitudinal sections were obtained and stained with hematoxylin-eosin for evaluation by light microscopy. For histometric analysis was used a $40 x$ objective and $8 x$ Zeiss Kpl eyepiece containing a Zeiss II integration grid with 10 parallel lines and 100 points symmetrically 
Table 1- Bacterial species investigated by checkerboard DNA-DNA hybridization

\begin{tabular}{|c|c|c|c|}
\hline Species & Strain & Species & Strain \\
\hline Actinomyces gerencseriae & $23860^{a}$ & $\begin{array}{l}\text { Fusobacterium nucleatum ss. } \\
\text { polymorphum }\end{array}$ & $10953^{a}$ \\
\hline Actinomyces israelii & $12102^{\mathrm{a}}$ & Fusobacterium nucleatum ss. vincentii & $49256^{a}$ \\
\hline Actinomyces naeslundii 1 & $12104^{a}$ & Fusobacterium periodonticum & $33693^{a}$ \\
\hline Actinomyces naeslundii 2 & $43146^{a}$ & Peptostreptococcus micros & $33270^{\mathrm{a}}$ \\
\hline Streptococcus gordonii & $10558^{a}$ & Prevotella intermedia & $25611^{a}$ \\
\hline Streptococcus intermedius & $27335^{a}$ & Prevotella nigrescens & $33563^{a}$ \\
\hline Streptococcus mitis & $49456^{a}$ & Streptococcus constellatus & $27823^{a}$ \\
\hline Streptococcus oralis & $35037^{a}$ & Tannerella Forsythia & $43037^{a}$ \\
\hline Streptococcus sanguis & $10556^{a}$ & Porphyromonas gingivalis & $33277^{a}$ \\
\hline $\begin{array}{l}\text { Aggregatibacter actinomycetemcomitans } \\
a \text { and } b\end{array}$ & $\begin{array}{l}43718^{a} \\
29523^{a}\end{array}$ & Treponema denticola & $\mathrm{B} 1^{\mathrm{b}}$ \\
\hline Capnocytophaga gingivalis & $33624^{a}$ & Gemella morbillorum & $27824^{a}$ \\
\hline Capnocytophaga ochracea & $33596^{a}$ & Leptotrichia buccalis & $14201^{\mathrm{a}}$ \\
\hline Capnocytophaga sputigena & $33612^{a}$ & Neisseria mucosa & $19696^{a}$ \\
\hline Eikenella corrodens & $23834^{a}$ & Prevotella melaninogenica & $25845^{a}$ \\
\hline Campylobacter gracilis & $33236^{a}$ & Propionibacterium acnes I and II & $\begin{array}{l}11827^{\mathrm{a}} \\
11828^{\mathrm{a}}\end{array}$ \\
\hline Campylobacter rectus & $33238^{a}$ & Selenomonas noxia & $43541^{a}$ \\
\hline Campylobacter showae & $51146^{a}$ & Streptococcus anginosus & $33397^{a}$ \\
\hline Eubacterium nodatum & $33099^{a}$ & Treponema socranskii & $\mathrm{S} 1^{\mathrm{b}}$ \\
\hline Fusobacterium nucleatum ss. nucleatum & $25586^{a}$ & Actinomyces odontolyticus & $17929^{a}$ \\
\hline Veillonella parvula & $10790^{a}$ & & \\
\hline
\end{tabular}

a Strains from ATCC (American Type Culture Collection, Rockville, MD)

b Strains from Forsyth Institute

distributed over a quadrangular area. Forty-five histological fields were selected per alveolus by systematic randomization ${ }^{30}$. The histological quantified variables were bone, connective tissue, inflammatory infiltrate, blood clot and empty spaces. Based on the 100-point grid, bone, connective tissue, inflammatory infiltrate, blood clot and empty spaces count was expressed by density (D). The density is the total of points of each variable divided per 100 points of the grid. The results were expressed by mean of density observed in each group and analyzed period.

\section{Statistical analysis}

Data normality was verified by KolmogorovSmirnov test. Data description was done by mean and $95 \%$ confidence interval of mean. Student's t test or Mann-Whitney Rank Sum Test ( $T$ ) was applied when Group I and II were compared in each period. One-way ANOVA or Kruskal-Wallis followed by Tukey's or Dunn's test took place when periods 6 , 15 and 28 days were compared in each group using GraphPad Prism 3.0 software (GraphPad Software Inc., San Diego, CA, USA). Spearman's correlation test was also undertaken in order to establish possible relationship among quantified variables.

\section{RESULTS}

Microbiological and CRP analysis

The bacterial species present in the inoculation material were Capnocytophaga ochracea, Fusobacterium nucleatum ss nucleatum, Prevotella melaninogenica, Streptococcus anginosus, Treponema socranskii and Streptococcus sanguis (Table 1).

The serum levels of $C$ reactive protein (CRP) were evaluated at $0,3,6,15$ and 28 days in both control (non-infected) and infected rats. The infected rats showed higher levels of serum CRP when compared to non-infected animals. At day 3 after infection the infected rats presented the highest serum levels of CRP, followed by a progressive decrease from 6 to 28 days after infection, but CRP levels remained still higher in infected compared to non-infected rats (Figure $2 \mathrm{~A}$ ).

\section{Histological features and histometric analysis \\ Group I}

At 6 days post-infection, the connective tissue was organized with proliferation of blood vessels around a central area still occupied by blood clot. Tissue organization allowed observation of a small number of thin newly formed bone trabeculae near 
of the alveolar walls and resorptive lacunae, mainly in the buccal wall (Figures $3 A$ and $3 B$ ). Fifteen days after infection, the connective tissue was well organized with a smaller number of blood vessels.
The newly formed bone trabeculae were still thin, but numerous, formed mainly from the lingual wall towards the central area of the socket. Focal areas of resorption are also observed at this period
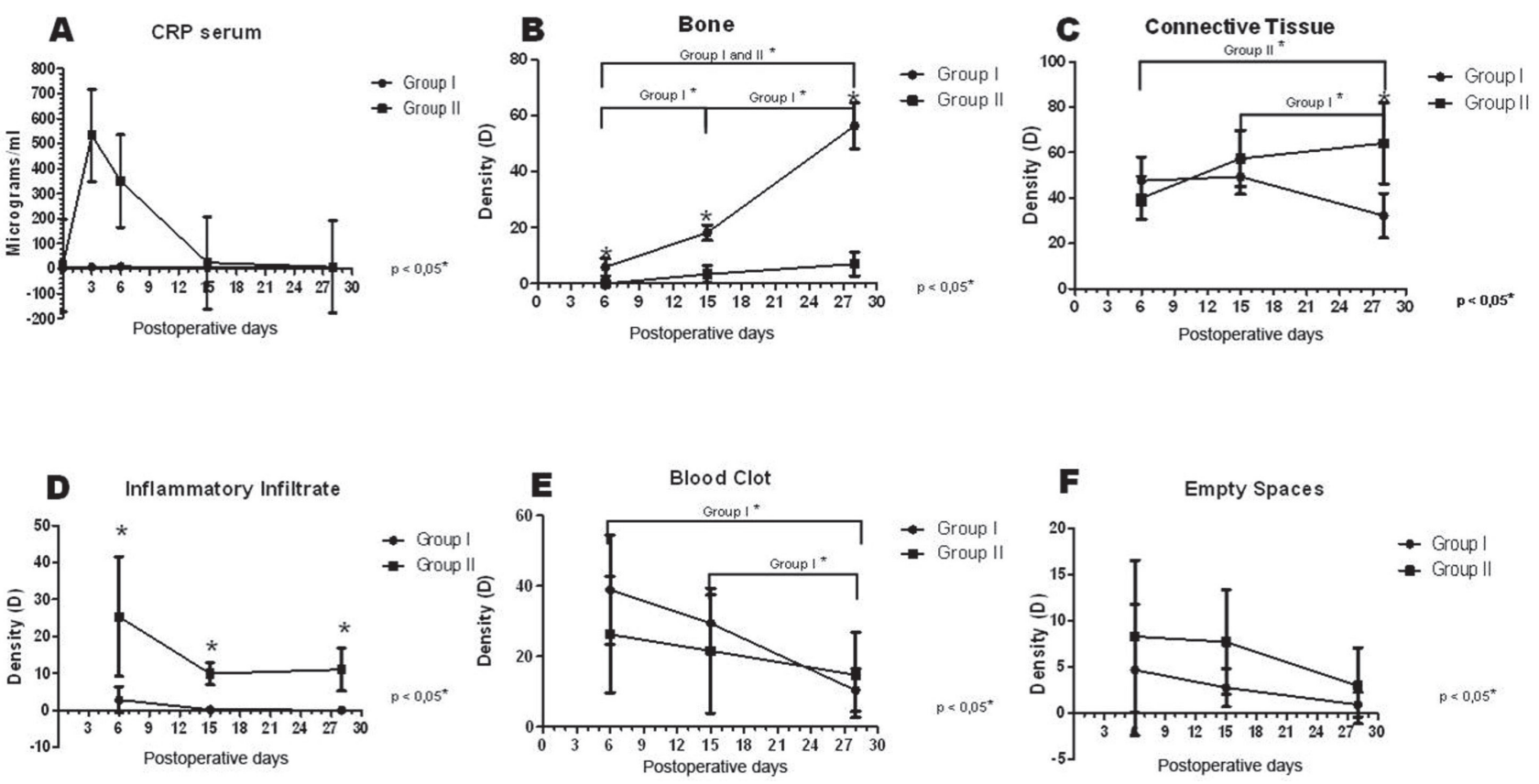

Figure 2- Increased serum CRP and delayed alveolar healing in experimental alveolitis rats. (A) CRP serum level results. (B to F) Histometric results: bone, connective tissue, inflammatory infiltrate, blood clot and empty space density, presented as means and standard deviations by group, in each period. Data were analyzed by groups using Student's t test or MannWhitney Rank Sum Test and by periods using one-way ANOVA or Kruskal-Wallis test and Tukey's or Dunn's test for multiple comparisons.

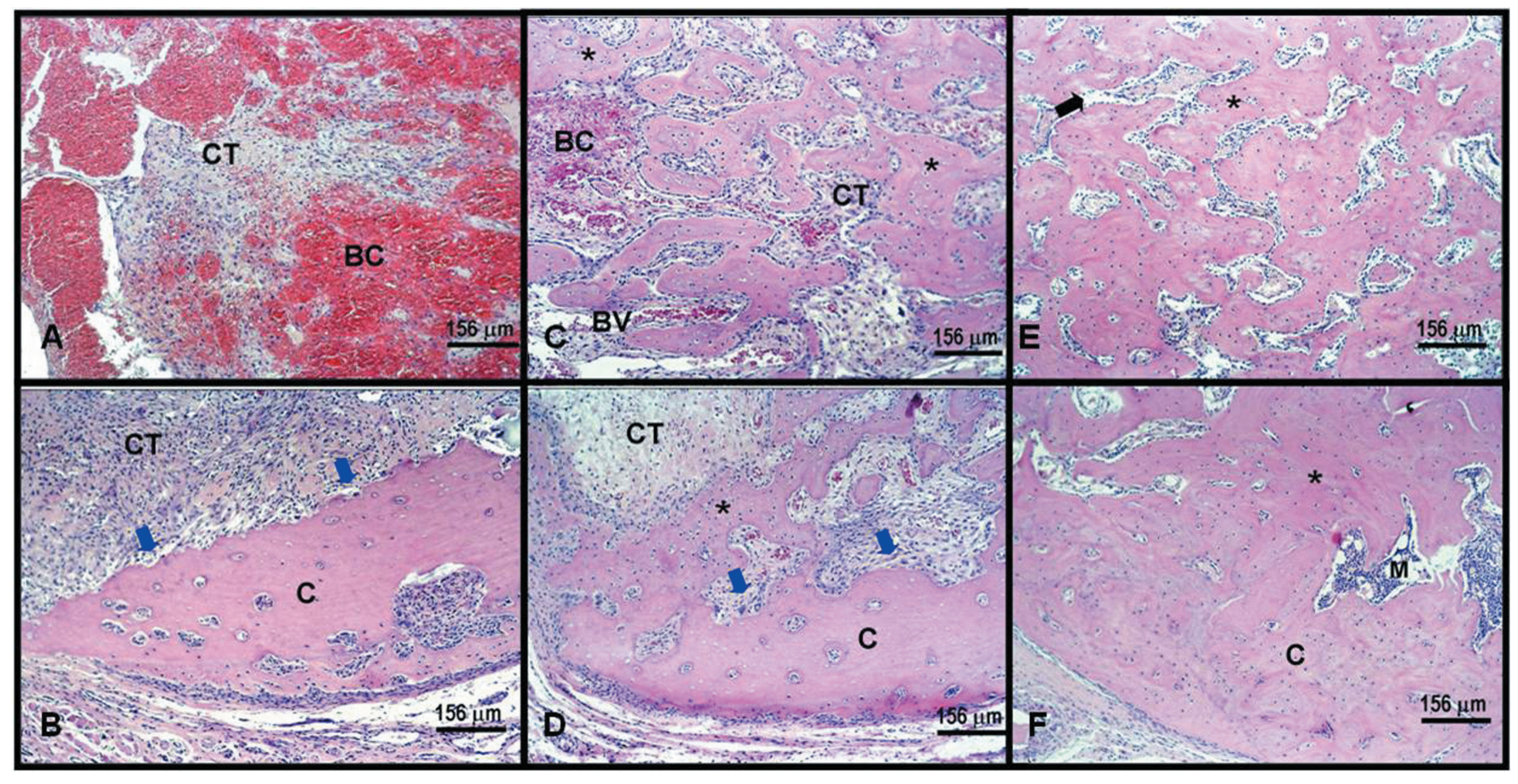

Figure 3- Non-infected rats present normal alveolar wound healing. Histological longitudinal specimens of Group I: 6 days postoperative ( $A$ and $B$ ) showing blood clot $(B C)$ and connective tissue (CT) filling the cervical portion of socket (A); and buccal cortical plate resorption (blue arrows) in (B); 15 days postoperative ( $C$ and $D$ ) showing rich vascularized connective tissue (CT), bone (asterisk) and blood clot (BC) in (C); new bone formation (asterisk), buccal cortical plate resorption (blue arrows) surrounded by connective tissue (CT) in (D); 28 days postoperative (E and F) displaying thick bone trabeculae (asterisk) and medular spaces surrounding the bone trabeculae. Hematoxylin-eosin 


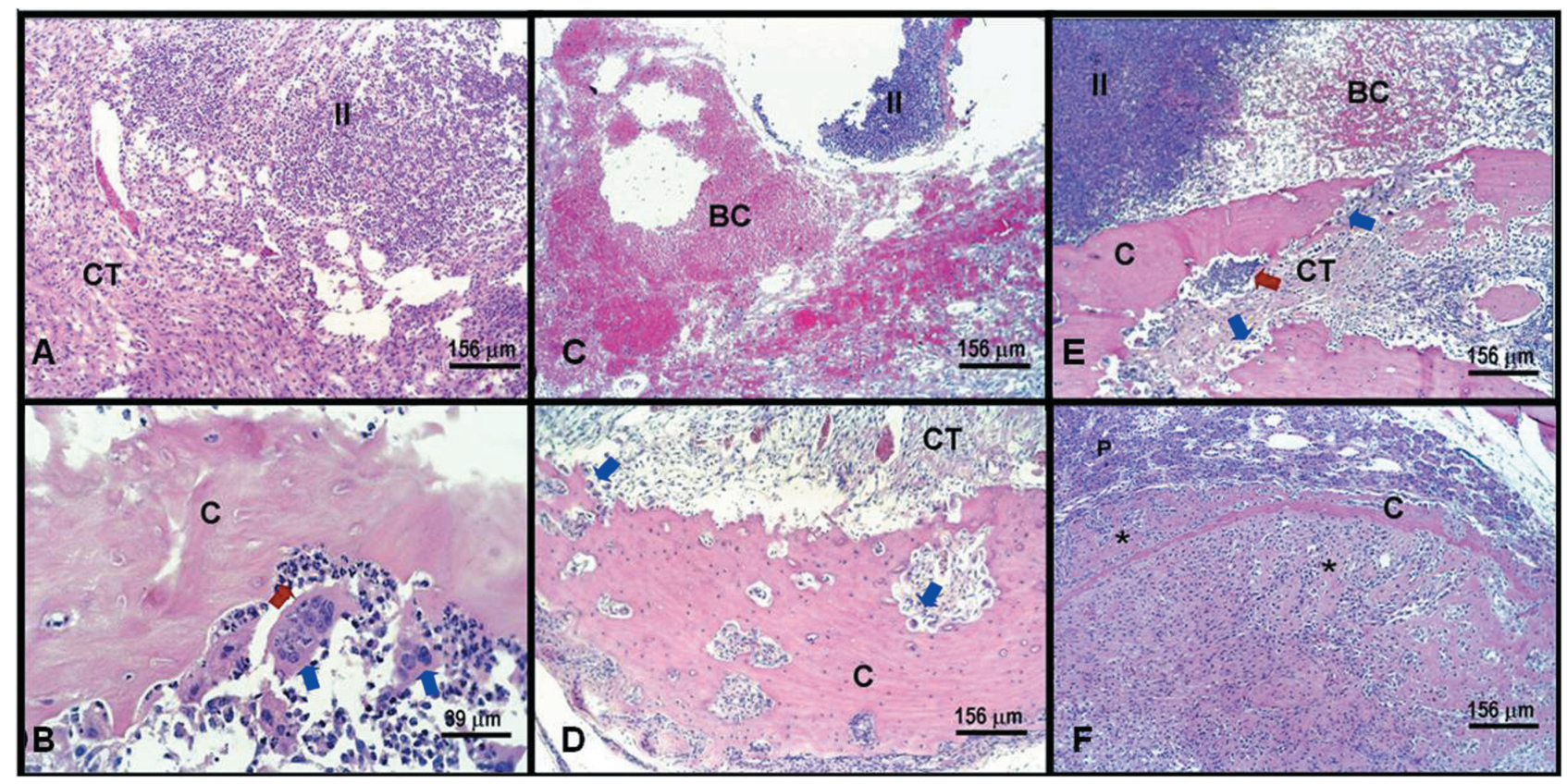

Figure 4- Experimentally induced alveolitis result in delayed alveolar healing. Histological longitudinal specimens of Group II: 6 days postoperative ( $A$ and $B$ ) showing inflammatory infiltrate with an exuberant presence of bacteria (II) surrounded by connective tissue (CT) occupying the cervical portion of socket (A); neutrophilic infiltrate predominant (red arrows), osteoclasts (blue arrows) resorbing buccal cortical plate in median portion of socket (B); 15 days postoperative (C and D) showing inflammatory infiltrate (II) and blood clot (BC) in (C); buccal cortical plate resorption (blue arrows) surrounded by connective tissue (CT) in (D); 28 days postoperative (E and $F$ ) displaying buccal cortical plate resorption (blue arrows), persistent inflammatory infiltrate and blood clot $(\mathrm{BC})$ remains in median third of socket (E); modest bone trabeculae (asterisk) attached to apical cortical plate (C) in apical third of socket $(F)$. Hematoxylin-eosin

Table 2- Correlation analysis among the histometric parameters throughout the alveolar healing in non-infected and infected rat sockets

\begin{tabular}{|c|c|c|c|c|}
\hline Group I & Connective Tissue & Inflammatory Infiltrate & Blood Clot & Empty Spaces \\
\hline \multirow[t]{2}{*}{ Bone } & $r s=-0.49$ & $r s=-0.48$ & $r s=-0.81$ & $r s=-0.22$ \\
\hline & $p=0.064$ & $p=0.069$ & $p=0.000^{*}$ & $p=0.426$ \\
\hline \multirow[t]{2}{*}{ Connective Tissue } & - & $r s=0.56$ & $r s=0.24$ & $r s=0.04$ \\
\hline & & $p=0.029^{*}$ & $p=0.374$ & $p=0.893$ \\
\hline \multirow[t]{2}{*}{ Inflammatory Infiltrate } & - & - & $r s=0.16$ & $r s=0.32$ \\
\hline & & & $p=0.549$ & $p=0.235$ \\
\hline \multirow[t]{2}{*}{ Blood Clot } & - & - & - & $r s=0.21$ \\
\hline & & & & $p=0.441$ \\
\hline Empty Spaces & - & - & - & - \\
\hline Group II & Connective Tissue & Inflammatory Infiltrate & Blood Clot & Empty Spaces \\
\hline \multirow[t]{2}{*}{ Bone } & $r s=0.84$ & $r s=-0.44$ & $r s=-0.57$ & $r s=-0.35$ \\
\hline & $p=0.000^{*}$ & $p=0.095$ & $p=0.025^{*}$ & $p=0.189$ \\
\hline \multirow[t]{2}{*}{ Connective Tissue } & - & $r s=-0.53$ & $\mathrm{rs}=-0.54$ & $\mathrm{rs}=-0.37$ \\
\hline & & $p=0.041^{*}$ & $p=0.035^{*}$ & $p=0.176$ \\
\hline \multirow[t]{2}{*}{ Inflammatory Infiltrate } & - & - & $r s=-0.03$ & $r s=0.34$ \\
\hline & & & $p=0.903$ & $p=0.204$ \\
\hline \multirow[t]{2}{*}{ Blood Clot } & - & - & - & $r s=-0.10$ \\
\hline & & & & $p=0.714$ \\
\hline Empty Spaces & - & - & - & - \\
\hline
\end{tabular}

Results of Spearman's correlation test (rs) and p value of variables in Group I and Group II. *statistically significant correlation $(p<0.05)$ 
(Figures 3C and 3D). When analyzed 28 days after infection, the connective tissue was well organized with a smaller number of blood vessels. The newly formed bone trabeculae were thick and numerous, with defined medullar spaces occupying almost all the surface of the median third, including the central portion of the socket (Figures $3 \mathrm{E}$ and $3 \mathrm{~F}$ ).

Group II

At 6 days after infection the connective tissue was not organized with a central area still occupied by blood clot and predominant polymorphonuclear (PMN) infiltrate near to the bottom of the socket. No newly formed bone trabeculae were observed, and resorption of alveolar walls was seen, mainly in the buccal wall (Figures $4 A$ and 4B). Fifteen days after infection, the connective tissue started to present signs of organization, but PMN infiltrate and blood clot were still observed, beyond buccal cortical plate resorption. Newly formed bone trabeculae were not evident in this period (Figures $4 C$ and 4D). At day 28 after infection, the connective tissue showed organization, but focal areas of PMN infiltrate and blood clot were observed, besides buccal cortical plate resorption. Isolated focuses of thin newly formed bone trabeculae in apical third were observed in some specimens (Figures 4E and 4F).

\section{DISCUSSION}

Regarding the use of rat socket, the method presented in this study was based on a previous work $^{21}$ that originated a large number of studies. In this experimental model, even considering the differences concerning to the animal resistance and chronology of alveolar healing, it may simulates situations that could occur in humans. The histometric analysis of different histological variables of alveolar healing in infected and noninfected alveolus is important to establish possible relations among variables in both situations. Such relations could originate to preventive or curative histometric or molecular assays.

The process of cellular repair occurs by secondary intention and is a fibroproliferative response, mediated by growth factors and cytokines, which aims to restore tissue to its original status ${ }^{26}$. It is a complex process that involves a sequence of events, has an onset marked by inflammation in response to an initial injury to the tissue. The strength of the repair process is represented by cellular differentiation and proliferation mediated by growth factors and cytokines that act at different stages, among which include: PDGF, FGF, TGF- $\beta$, TNF, IL- 1 ; $V_{E G F}{ }^{26}$. It is known that several mechanisms are involved in the formation of mature bone tissue, and this process depends on the formation of an initial blood clot stage. Its chronology can be divided into four stages after the formation and stabilization of the blood clot. The phase of cell proliferation, which starts with vascular events and cellular inflammation, is responsible for clot formation and development of tissue from the replacement of granulation tissue, where many cells and fibroblasts derived from the periodontal ligament and bone marrow differentiate and proliferate. In this phase, the activity of fibroblasts is intense and they synthesize the collagen fibers and amorphous substance that are essential to connective tissue maturation, a phase in which there is a reduction of the number of cells and vessels. After begins the formation of organic matrix by osteoblasts followed by matrix mineralization and formation of bone trabeculae to the corresponding stage of differentiation and bone mineralization ${ }^{27}$. Bone tissue formation is dependent on the activation and differentiation of osteoblasts, leading to the production of different proteins (collagenous and noncollagenous), and enzymes such as alkaline phosphatase, which will be responsible for the mineralization of bone tissue formation.

In the present study, Wistar rats (Rattus novergicus albinus) subjected to socket inoculation of a suppurative secretion including Capnocytophaga ochracea, Fusobacterium nucleatum ss nucleatum, Prevotella melaninogenica, Streptococcus anginosus, Treponema socranskii and Streptococcus sanguis developed suppurative alveolitis, characterized by expression of high levels of CRP, clinical signs of suppurative infection and delayed alveolar healing. The aforementioned bacteria were detected by checkerboard DNA-DNA hybridization ${ }^{24}$ in the suppurative secretion from donor rats used to the socket inoculation which resulted in experimental alveolitis. These microorganisms were detected among a panel of 39 different bacterial species commonly present in the oral cavity (Table 1 ). Several of these species, specially the Gramnegative anaerobes have been associated with oral infections, such as periodontal diseases, endodontic lesions and pericoronitis $3,19,22,23$. Nitzan, et al. ${ }^{19}$ (1978) showed a possible relationship between anaerobic bacteria (predominant in pericoronitis lesions) and alveolitis, demonstrating fibrinolytic activity in cultures of Treponema denticola, present in periodontal disease. Melo Júnior ${ }^{16}$ (2002) detected some Streptococci species, Enterococcus, Bacillus corineforme, Proteus vulgaris, Pseudomona aeruginosa, Citrobacter freundii and Escherichia coli in alveolar biological content in acutely infected sockets of rats. Several studies, including the present one, have shown that material obtained from sites of pericoronitis teems with spirochetes and fusobacteria ${ }^{19,20}$. Their presence in pericoronitis would be consistent with the high incidence (up $88 \%$ ) of alveolitis following extractions associated with this inflammatory process ${ }^{19,20}$. Therefore, 
periodontopathogens inoculated into the socket could simulate the pattern of disturbing presented in clinical situations of alveolitis, based on microbial theories $7,19,22$. However, it is important to state that other microorganisms could be present in the inoculation material used in this study, which were not investigated by the applied diagnostic test. Some were related to other alveolar infection studies, such as Bacteriodes fragilis, Enterococcus, Bacillus corineforme, Proteus vulgaris, Pseudomonas aeruginosa, Citrobacter freundii, Escherichia coli, Staphilococcus and other Streptococci ${ }^{10,19}$.

Our findings demonstrate that the inoculation of suppurative secretion containing gram-negative anaerobes and gram-positive facultative associated with pericoronitis and periodontal disease in humans results in $100 \%$ of effectiveness of bacterial colonization of the socket, and leads to the development of experimental suppurative alveolitis. In fact, the experimental infection was really effective and the high levels of serum CRP were found after infection. Similarly, high levels of CRP were found during the course of experimental periodontal disease in rats, establishing CRP as interesting systemic mediator of disseminated infection ${ }^{11}$. At present, no study has evaluated systemic parameters after induced alveolitis in animals or clinical trials, such as CRP serum levels. The results of the present study illustrate the systemic dissemination of acutely infection that can possibly evolve to bacteremia and other systemic infections in clinical situations. Indeed, acutely infected sockets are sometimes described as being associated with parameters of systemic infection, such as fever.

Due to intense inflammatory reaction induced by the infection, the reparative process is delayed, and furthermore is preceded by an extensive osteoclastic activity, which sometimes causes sequester formation. At different times after the extraction, granulation tissue starts growing into the alveolus through the perforations of the lamina dura. The alveolar wound is gradually filled up from the bottom with granulation tissue, and at the same time the reepithelization starts. After the socket has been filled with granulation tissue and covered by epithelium, healing takes its normal course $^{4}$. Therefore, in spite of pain, odor and other symptoms, acutely infected sockets go on a healing process, though it is significantly delayed in comparison to healthy sockets.

The histometric analysis showed a uniform bone formation in Group I sockets, being significant amongst themselves (Figure 2B). There was correlation between the increase of bone tissue density and blood clot reduction from 6 to 28 days, and significant connective tissue density reduction from 15 to 28 days correlated with inflammatory infiltrate density reduction (Table 2). Group II presented a delay in bone tissue formation. Lower increase of bone density among periods was also observed (Figure 2B). There was positive correlation between bone density and connective tissue increase correlated with inflammatory infiltrate and blood clot density reduction (Table 2 ), showing slower wound healing in this group.

\section{CONCLUSIONS}

It may be concluded that this model mimics the characteristics of suppurative alveolitis (acutely infected socket), including pus formation at socket bottom, gingival edema, similar bacteria involved, systemic involvement and disturbed alveolar healing. Group I (non-infected) showed higher bone density of at all studied periods, than Group II (infected), confirming the alveolar healing disturbing in infected sockets, which could simulate clinical situations of dry socket. Group II presented higher CRP levels at all studied periods compared to Group I, proving the potential of experimentally induced infection. This model seems to be useful to study preventive or curative modalities of alveolitis and other features involved in infected and noninfected alveolar wound healing.

\section{ACKNOWLEDGMENTS}

We would like to thank Dr. Elerson Gaetti Jardim Júnior (FOA-UNESP) for providing the inoculation material employed in this study.

\section{REFERENCES}

1- Adeyemo WL, Ladeinde AL, Ogunlewe MO. Influence of trans-operative complications on socket healing following dental extractions. J Contemp Dent Pract. 2007;8:52-9.

2- Awang MN. The aetiology of dry socket: a review. Int Dent J. 1989;39:236-40.

3- Baumgartner JC, Khemaleelakul SU, Xia T. Identification of spirochetes (treponemes) in endodontic infections. J Endod. 2003;29:794-7.

4- Birn $\mathrm{H}$. Etiology and pathogenesis of fibrinolytic alveolitis ("dry socket"). Int J Oral Surg. 1973;2:211-63.

5- Cardoso CL, Rodrigues MTV, Ferreira O Jr, Garlet GP, Carvalho PSP. Clinical concepts of dry socket. J Oral Maxillofac Surg. 2010;68:1922-32.

6- Carvalho PS, Mariano RC, Okamoto T. The treatment of fibrinolytic alveolitis with rifamycin b diethylamide associated with gelfoam: a histological study. Braz Dent J. 1997;8:3-8.

7- Catellani JE. Review of factors contributing to dry socket through enhanced fibrinolysis. J Oral Surg. 1979;37:42-6.

8- Cheung LK, Chow LK, Tsang MH, Tung LK. An evaluation of complications following dental extractions using either sterile or clean gloves. Int J Oral Maxillofac Surg. 2001;30:550-4.

9- Cohen ME, Simecek JW. Effects of gender-related factors on the incidence of localized alveolar osteitis. Oral Surg Oral Med Oral Pathol Oral Radiol Endod. 1995;79:416-22. 
10- Feres M, Haffajee AD, Allard K, Som S, Goodson JM, Socransky SS. Antibiotic resistance of subgingival species during and after antibiotic therapy. J Clin Periodontol. 2002;29:724-35.

11- Garlet GP, Cardoso CR, Campanelli AP, Ferreira BR, AvilaCampos MJ, Cunha FQ, et al. The dual role of p55 tumour necrosis factor-alpha receptor in Actinobacillus actinomycetemcomitansinduced experimental periodontitis: host protection and tissue destruction. Clin Exp Immunol. 2007;147:128-38.

12- Goldberg $\mathrm{MH}$, Nemarich AN, Marco WP $2^{\text {nd }}$. Complications after mandibular third molar surgery: a statistical analysis of 500 consecutive procedures in private practice. J Am Dent Assoc. $1985 ; 111: 277-9$.

13- Larsen PE. The effect of a chlorhexidine rinse on the incidence of alveolar osteitis following the surgical removal of impacted mandibular third molars. J Oral Maxillofac Surg. 1991;49:932-7. 14- Lilly GE, Osbon DB, Rael EM, Samuels HS, Jones JC. Alveolar osteitis associated with mandibular third molar extractions. J Am Dent Assoc. 1974;88:802-6.

15- MacGregor AJ. Aetiology of dry socket: a clinical investigation. $\mathrm{Br}$ J Oral Surg. 1968;6:49-58.

16- Melo Junior EJ, Raposo MJ, Lisboa Neto JA, Diniz MF, Marcelino Junior CA, Sant'Ana AE. Medicinal plants in the healing of dry socket in rats: microbiological and microscopic analysis. Phytomedicine. 2002;9:109-16.

17- Mitchell R. Treatment of fibrinolytic alveolitis by a collagen paste (Formula K). A preliminary report. Int J Oral Maxillofac Surg. 1986;15:127-33.

18- Monaco G, Staffolani C, Gatto MR, Checchi L. Antibiotic therapy in impacted third molar surgery. Eur J Oral Sci. 1999;107:437-41. 19- Nitzan D, Sperry JF, Wilkins TD. Fibrinolytic activity of oral anaerobic bacteria. Arch Oral Biol. 1978;23:465-70.
20- Nitzan DW. On the genesis of "dry socket". J Oral Maxillofac Surg. 1983;41:706-10.

21- Okamoto T, Russo MC. Wound healing following tooth extraction. Histochemical study in rats. Rev Fac Odontol Araçatuba. 1973;2:153-64.

22- Rud J. Removal of impacted lower third molars with acute pericoronitis and necrotising gingivitis. $\mathrm{Br}$ J Oral Surg. 1970:7:15360.

23- Socransky SS, Haffajee AD. Periodontal microbial ecology. Periodontol. 2005;38:135-87.

24- Socransky SS, Smith C, Martin L, Paster BJ, Dewhirst FE, Levin AE. "Checkerboard" DNA-DNA hybridization. Biotechniques. 1994;17:788-92.

25- Sorensen DC, Preisch JW. The effect of tetracycline on the incidence of postextraction alveolar osteitis. J Oral Maxillofac Surg. 1987;45:1029-33.

26- Sweet JB, Butler DP. Increased incidence of postoperative localized osteitis in mandibular third molar surgery associated with patients using oral contraceptives. Am J Obstet Gynecol. 1977;127:518-9.

27- Sweet JB, Macynski AA. Effect of antimicrobial mouth rinses on the incidence of localized alveolitis and infection following mandibular third molar oral surgery. Oral Surg Oral Med Oral Pathol. 1985;59:24-6.

28- Trieger N, Schlagel GD. Preventing dry socket. A simple procedure that works. J Am Dent Assoc. 1991;122:67-8.

29- Tsirlis AT, Iakovidis DP, Parissis NA. Dry socket: frequency of occurrence after intraligamentary anesthesia. Quintessence Int. 1992;23:575-7.

30- Weibel ER. Stereological principles for morphometry in electron microscopic cytology. Int Rev Cytol. 1969;26:235-302. 